TITLE:

\title{
Effects of astaxanthin-enriched yeast on mucosal IgA induction in the jejunum and ileum of weanling mice.
}

\section{$\operatorname{AUTHOR(S):~}$}

Nagayama, Tatsuhiko; Sugimoto, Miki; Ikeda, Shuntaro; Kume, Shinichi

\section{CITATION:}

Nagayama, Tatsuhiko ... [et al]. Effects of astaxanthin-enriched yeast on mucosal IgA induction in the jejunum and ileum of weanling mice.. Animal science journal: Nihon chikusan Gakkaihō 2013, 85(4): 449-453

\section{ISSUE DATE:}

2013-12-12

URL:

http://hdl.handle.net/2433/198559

\section{RIGHT:}

This is the peer reviewed version of the following article: Nagayama, T., Sugimoto, M., Ikeda, S. and Kume, S. (2014), Effects of astaxanthin-enriched yeast on mucosal IgA induction in the jejunum and ileum of weanling mice. Animal Science Journal, 85: 449-453, which has been published in final form at http://dx.doi.org/10.1111/asj.12154.; This is not the published version. Please cite only the published version.; この論文は出版社版でありません。引用の際には出版社 版をご確認ご利用ください。 
1 Effects of astaxanthin-enriched yeast on mucosal IgA induction in the jejunum

\section{and ileum of weanling mice}

Tatsuhiko NAGAYAMA, Miki SUGIMOTO, Shuntaro IKEDA and Shinichi KUME*

Graduate School of Agriculture, Kyoto University, Kyoto 606-8502, Japan

Correspondence author: Shinichi Kume,

Graduate School of Agriculture, Kyoto University, Kitashirakawa Oiwake-cho, Sakyo-ku, Kyoto 606-8502, Japan

Tel) +81-75-753-6325, Fax) +81-75-753-6345, E-mail: kume@kais.kyoto-u.ac.jp

* Corresponding to: Shinichi Kume, Graduate School of Agriculture, Kyoto University,

Sakyo-ku, Kyoto 606-8502, Japan

E-mail: kume@kais.kyoto-u.ac.jp 


\section{ABSTRACT}

2 The present study was conducted to clarify the effects of astaxanthin-enriched yeast on the concentration of IgA, the numbers of IgA antibody-secreting cells (ASC) and the mRNA

4 expression of IgA C-region in the jejunum and ileum of weanling mice. Weanling mice were fed

5 rodent feed or astaxanthin-enriched yeast-supplemented rodent feed for 7, 14 or 21 days.

6 Supplemental astaxanthin-enriched yeast increased the numbers of IgA ASC in the jejunum and

7 ileum after 7, 14 and 21 days of treatment. Supplemental astaxanthin-enriched yeast increased

8 IgA concentrations in the jejunum after 21 days of treatment, but IgA concentrations in the ileum

9 were not affected by the treatment. The mRNA expressions of IgA C-region in the jejunum after 14 and 21 days of treatment and the ileum after 14 days of treatment were enhanced by supplementation of astaxanthin-enriched yeast. These results indicate that supplementation of astaxanthin-enriched yeast is effective to enhance the numbers of IgA ASC in the jejunum and

13 ileum and IgA concentrations in the ileum of weanling mice.

Key words: astaxanthin, IgA, ileum, jejunum, weanling mice 
2

4

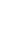

\section{INTRODUCTION}

Carotenoids and retinoids are present in many foods of plant and animal origin, and retinoids have the potential to mediate or induce proliferative and differentiating effects on several immune-component cells (Rühl 2007). The improvement of immune system is required to prevent diarrhea in neonates, and IgA provides protection against microbial antigens at mucosal surfaces in animals and humans (Ertesvåg et al. 2009; Fagarasan \& Honjo 2003). Supplemental vitamin A and $\beta$-carotene enhance the immune system in neonates (Bendich 1989; Chew \& Park 2004), but $\beta$-carotene deficient calves were found to have a higher incidence of diarrhea in the first week of life (Kume \& Toharmat 2001). In the previous studies (Nishiyama et al. 2011a,b), supplemental $\beta$-carotene increased not only serum $\beta$-carotene concentrations in neonatal calves but also IgA transfer from maternal milk to neonatal mice.

Reactive oxygen species (ROS) are highly reactive and associated with oxidative stress in the body, and ROS can destroy cellular membranes, cellular proteins and nucleic acids (Chew \& Park 2004). Carotenoids have an antioxidant activity and reduce the toxic effects of ROS in the mucosal membrane. Dietary carotenoids such as lutein, cantaxanthin, lycopene and astaxanthin do not have a pro-vitamin A activity, but these carotenoids are active to enhance the cell-mediated and humoral immune response in animals and humans (Chew \& Park 2004). Astaxanthin shows notable antioxidant properties and is twice as effective as $\beta$-carotene as a scavenger of peroxyl radicals (Goto et al. 2001). Astaxanthin prevents the oxidative injury in human lymphocytes (Bolin et al. 2010; Campoio et al. 2011), inhibits the tumor growth (Chew \& Park 2004) and ameliorates the embryonic development impaired by heat stress (Namekawa et al. 2010). Because $\beta$-carotene supplementation is effective to enhance mucosal IgA induction in the jejunum or ileum in weanling mice (Nishida et al. 2013), astaxanthin supplementation has been expected to enhance the mucosal immune induction in neonates. 
The objective of the present study was conducted to clarify the effects of astaxanthin-enriched yeast on the concentrations of IgA, the numbers of IgA antibody-secreting cells (ASC) and the mRNA expression of IgA C-region in the jejunum and ileum of weanling mice.

\section{MATERIALS AND METHODS}

\section{Animals and diets}

Male weanling ICR mice $(n=49)$ at 21 days of age were purchased from Clea Japan (Tokyo, Japan). They were housed in individual polycarbonate cages and maintained in an air-conditioned room $\left(24 \pm 2^{\circ} \mathrm{C}\right)$ under controlled lighting conditions (light-dark cycle, 14:10 h). They received humane care in accordance with "Regulation on Animal Experimentation at Kyoto University" (Animal Research Committee, Kyoto University, revised 2007).

Weanling mice were randomly allocated to the control or astaxanthin group at 21 days of age. Mice in the control group were fed rodent feed (Oriental Yeast, Tokyo, Japan) for 7 (n=8), 14 (n= 8) or $21(n=8)$ days, and those in the astaxanthin group were fed astaxanthin-enriched yeast -supplemented rodent feed for $7(n=8), 14(n=9)$ or $21(n=8)$ days. The rodent feed contained 55.3\% NFE, 23.6\% CP, 5.1\% crude fat, 5.8\% crude ash, 1283IU/100g vitamin A and 9.1mg/100g vitamin E. Astaxanthin was derived from dried yeast product of phaffia rhodozyma (Aquasta ${ }^{\mathrm{TM}}$, Naturxan Co Ltd., Colombia, USA), which contained 58.3\% NFE, 20.8\% CP, 9.6\% crude fat, $2.6 \%$ crude ash, $1.2 \%$ astaxanthin and $1030 \mathrm{IU} / 100 \mathrm{~g}$ vitamin A. For the astaxanthin group, $1 \%$ Aquasta was mixed with the rodent feed and astaxanthin concentration in the diet was $120 \mathrm{mg} / \mathrm{kg}$, which was established about 2 times higher than the dietary $\beta$-carotene level at $50 \mathrm{mg} / \mathrm{kg}$ as previously described (Nishida et al. 2013). All mice were allowed free access to water and feed. Body weights and feed intake of mice were measured at 11.00 hours every day. 
2 Sample collection

3 Blood samples from mice in the control and astaxanthin groups after 7, 14 and 21 days of 4 treatment were obtained by cardiac puncture under anaesthesia with Avertin 5 (2,2,2-tribromoethanol, Sigma-Aldrich Chemical, St Louis, MO, USA), and then jejunum, ileum 6 and rectum feces were removed after euthanasia by cervical dislocation. The samples of jejunum

7 and ileum were immediately frozen in dry ice-cooled isopentane (2-methylbutane; Wako Pure 8 Chemicals, Osaka, Japan) for immunohistochemical analysis or frozen in liquid nitrogen and 9 stored at $-80^{\circ} \mathrm{C}$ for IgA immunoassay and semi-quantitative RT-PCR. Blood samples were left to stand at room temperature for $1 \mathrm{~h}$ and then centrifuged at $3000 \mathrm{x}$ g for $15 \mathrm{~min}$. The samples of serum and rectum feces were stored at $-20^{\circ} \mathrm{C}$ until IgA analysis.

\section{IgA immunoassay and immunohistochemical analysis}

IgA immunoassay of serum, jejunum, ileum and feces and immunohistochemical analysis of jejunum and ileum were carried out as previously described (Nishiyama et al. 2011a). IgA concentrations were measured using the Mouse IgA ELISA Quantitation Kit (Bethyl Laboratories, Montgomery, TX, USA) and ELISA Starter Accessory Package (Bethyl Laboratories) according to the manufacturer's instructions. The sections obtained from the immunohistochemical analysis were examined under an epifluoresence microscope (BX50; Olympus, Tokyo, Japan), and the resulting images were analyzed using Image J software (National Institute of Health, Bethesda, MD, USA). IgA-positive cells in the jejunum and ileum were counted in the lamina propria of villi in eight randomised villi from each mouse and shown as IgA ASC/unit area of the lamina propria of villi (unit $=10000 \mu \mathrm{m}^{2}$ ).

\section{Semi-quantitative RT-PCR}


1 The mRNA expression of IgA C-region in the jejunum and ileum was examined by

2 semi-quantitative RT-PCR. Total RNA was extracted from homogenized jejunum and ileum samples from each mouse using an RNeasy Mini Kit (Qiagen, Germantown, MD, USA). Complementary DNA was synthesised with oligo-(dT) primer using an SuperScript III First-Strand Synthesis System for RT-PCR (Invitrogen Calisbad, CA, USA) from $4 \mu \mathrm{g}$ RNA of each sample. The PCR was performed using Pt PCR Super Mix kit (Invitrogen). The primer pairs for IgA C-region were as follows: forward: 5-TGCACAGTTACCCATCCTGA-3, reverse: 5-GCACCAGCACTTCTTTAGGG-3. The PCR procedure was as follows: after $94^{\circ} \mathrm{C}$ for $5 \mathrm{~min}$ to denature DNA, PCR was performed for thirty-three cycles in the jejunum or thirty cycles in the ileum at $94^{\circ} \mathrm{C}$ for $1 \mathrm{~min}, 53^{\circ} \mathrm{C}$ for $1 \mathrm{~min}, 72^{\circ} \mathrm{C}$ for $1 \mathrm{~min}$, then at $72^{\circ} \mathrm{C}$ for $7 \mathrm{~min}$. The PCR products were electrophoresed in $2 \%$ agarose gel and stained with $1 \mathrm{mg} / \mathrm{ml}$ ethidium bromide solution. After electrophoresis, the gels were recorded with a digital recorder and then mRNA expression levels were semi-quantified using Image J software. (National Institute of Health, Bethesda, MD, USA). The relative abundance of specific mRNA was normalised by the abundance of glyceraldehydes 3-phosphate dehydrogenase (GAPDH) mRNA. The primer pairs for GAPDH were as follows: forward: 5-GGGTGGAGCCAAACGGGTC-3, reverse: 5-GGAGTTGCTGTTGAAGTCGC-3. The PCR procedure was as follows: after $94^{\circ} \mathrm{C}$ for $5 \mathrm{~min}$ to denature DNA, PCR was performed for twenty-seven cycles in the jejunum or twenty-three cycles at $94^{\circ} \mathrm{C}$ for $1 \mathrm{~min}, 59^{\circ} \mathrm{C}$ for $1 \mathrm{~min}, 72^{\circ} \mathrm{C}$ for $1 \mathrm{~min}$, then at $72^{\circ} \mathrm{C}$ for $7 \mathrm{~min}$.

\section{Statistics}

Data from body weight and feed intake were analysed by least squares ANOVA using the general linear model procedure of Statistical Analysis Systems (SAS 1997). The model was as follows:

$$
Y_{i j k}=\mu+T_{i}+M_{(i) j}+D_{k}+T D_{i k}+e_{i j k}
$$

where $\mu$ is the overall mean, $T_{i}$ is the effect of treatment, $M_{(i) j}$ is the random variable of mice 
1 nested in treatment, $D_{k}$ is the effect of day, $T D_{i k}$ is the interactions and $\mathrm{e}_{i j k}$ is the residuals. The 2 general linear model procedure of Statistical Analysis Systems (SAS 1997) was used to analyze

\section{RESULTS}

\section{IgA concentration in serum and tissues}

Body weight gains and feed intake of mice during 21 days of treatment as well as those of mice during 7 and 14 days of treatment (data not shown) were similar between groups (Fig. 1). IgA concentrations in the jejunum of the astaxanthin group were significantly higher $(P<0.01)$ than those of the control group after 21 days of treatment, but IgA concentrations in the ileum, serum and feces of mice after 7, 14 and 21 days of treatment were not affected by the treatment (Table 1). Compared with IgA concentrations of mice after 7 days of treatment, IgA concentrations in the jejunum, ileum, serum and feces increased $(P<0.001)$ after 21 days of treatment.

\section{IgA antibody-secreting cells in tissues}

The numbers of IgA ASC in the jejunum of the astaxanthin group were significantly higher than those of the control group after $7(P<0.001), 14(P<0.001)$ and $21(P<0.01)$ days of treatment (Fig. 2). The numbers of IgA ASC in the ileum of the astaxanthin group were significantly higher $(P<0.001)$ than those of the control group after 7, 14 and 21 days of treatment. Compared with the numbers of IgA ASC of mice after 7 days of treatment, the numbers of IgA ASC in the jejunum and ileum of mice increased $(P<0.001)$ after 21 days of treatment.

\section{Expression of mRNA in tissues}


1 The mRNA expression of IgA C-region in the jejunum of the astaxanthin group was significantly higher $(P<0.05)$ than that of the control group after 14 and 21 days of treatment (Table 2). The mRNA expression of IgA C-region in the ileum of the astaxanthin group was significantly higher $(P<0.05)$ than that of the control group after 14 days of treatment.

\section{DISCUSSION}

7

IgA antibodies in the intestines are specific to antigens of the intestinal microflora and act to limit the penetration of commensal intestinal bacteria through the neonatal intestinal epithelium (Harris et al. 2006). Peyer's patches in the gut-associated lymphoid tissue are the main site for the generation of $\operatorname{IgA}^{+} \mathrm{B}$ cells, and plasmablasts differentiated by $\operatorname{IgA}^{+} \mathrm{B}$ cells preferentially home on the gut lamina propria through the thoracic duct and blood by the expression of homing ligands and receptors (Ertesvåg et al. 2009; Fagarasan \& Honjo 2003). The gut-associated lymphoid tissue dendritic cells rely on retinoic acid (RA) to induce IgA class switching, and RA is essential for the imprinting of gut-homing receptors on $\mathrm{T}$ and $\mathrm{B}$ cells and contributes to IgA production (Mora \& von Andrian 2009). In the previous study (Nishida et al. 2013), supplemental $\beta$-carotene at $50 \mathrm{mg} / \mathrm{kg}$ in the diet increased the numbers of IgA ASC in the jejunum of weanling mice after 7 , 14 and 21 days of treatment and the ileum after 14 and 21 days of treatment, and the effects are mainly due to the RA-mediated immune response.

Astaxanthin is a typical fat-soluble antioxidant, which scavenges ROS and blocks lipid peroxidation (Goto et al. 2001). A number of endogenous antioxidants were produced in the body and scavenges harmful ROS to maintain the normal cellular function and health, but dietary sources of antioxidants are required to eliminate excessive ROS in the body under conditions of high oxidative stress (Chew \& Park 2004). In the present study, the numbers of IgA ASC and IgA concentrations in the jejunum and ileum of weanling mice increased with age and supplemental 
astaxanthin-enriched yeast, which contained $120 \mathrm{mg} / \mathrm{kg}$ astaxanthin in the diet, increased the numbers of IgA ASC in the jejunum and ileum of weanling mice after 7, 14 and 21 days of treatment. After weaning, the intestinal mucosa of mice is exposed to a wide variety of exogenous antigens due to the sudden change in the diet and the numbers of Ig-secreting cells are likely to increase (Nishida et al. 2013; Van del Heijden et al. 1988). Thus, our data indicate that astaxanthin-enriched yeast as well as $\beta$-carotene is effective to increase the numbers of IgA ASC in the jejunum and ileum of weanling mice.

Chemokines are transmembrane proteins that play important roles in innate and acquired immunity and chemokine ligand CCL25 is selectively expressed in the small intestine (Mora et al. 2006; Morteau et al. 2008). Supplemental $\beta$-carotene enhanced the mRNA expression of CCL25 in the jejunum of weanling mice after 14 and 21 days of treatment, which contributed to the mucosal immune induction by the increased homing of IgA ASC to the jejunum (Nishida et al. 2013). Because astaxanthin scavenges ROS in the mucosal membrane of intestines, the increased homing of IgA ASC to the guts in the present study may be partly due to the antioxidant-mediated immune response owing to the activated homing ligands. On the other hand, the dry yeast supplementation of Saccharomyces cerevisiae at $0.05 \%$ in the diet showed the increase of IgG level in colostrum and the maintenance of IgA level in milk of sows, although the dry yeast supplementation at 0.05 and $0.5 \%$ in the diet displayed immunostimulatory effects on maternal immunity (Zannello et al. 2013). Because of the useful effects of the dry yeast on IgA level in milk of sows, further study is needed to clarify the effects of astaxanthin or dry yeast on the homing of IgA ASC to the intestines.

Supplementation of vitamin A and carotenoids affects the immune-cell function during ontogenesis (Garcia et al. 2003), and vitamin A-depleted mice exhibit impaired IgA secretion in mucosal tissues of the small bowel (Mora et al. 2006). Supplemental $\beta$-carotene in weanling mice increased the concentrations of IgA and the mRNA expression of IgA C-region in the jejunum 
1 after 14 and 21 days of treatment, but IgA concentrations in the ileum were not affected by

$2 \quad \beta$-carotene supplementation (Nishida et al. 2013). In the present study, supplemental astaxanthin-enriched yeast increased the concentrations of IgA and the mRNA expressions of IgA C-region in the jejunum after 21 days of treatment, but IgA concentrations in the ileum, serum and feces were not affected by astaxanthin-enriched yeast supplementation. These results suggest that a long-term supplementation of astaxanthin-enriched yeast is needed for enhancing the mucosal IgA induction in the jejunum of weanling mice owing to the increase in the concentrations of IgA, the numbers of IgA ASC and the mRNA expressions of IgA C-region.

IgA antibodies in the intestines are mainly secreted as dimers after incorporation of the $\mathrm{J}$ chain and association with polymeric Ig receptor (pIgR), and the transport of IgA antibodies from IgA ASC into the intestines is regulated by pIgR (Fagarasan \& Honjo 2003). Supplementation of fructo-oligosaccharides in mice after weaning increased not only the concentrations of IgA but also the expression of pIgR in the ileum and colon (Nakamura et al. 2004). On the other hand, coumestrol administration in maternal mice during pregnancy and lactation increased the number of IgA ASC in mammary glands, but had no effect on the concentrations of milk IgA and the mRNA expression of pIgR in mammary glands (Wang et al. 2013). Thus, the increased IgA concentrations in the jejunum of weanling mice after 21 days of treatment in the present study may be due to the increased expression of pIgR caused by astaxanthin-enriched yeast supplementation. However, further study is needed to clarify the exact mechanism of astaxanthin for promoting mucosal IgA induction in the intestines of weanling mice and preventing diarrhea.

\section{ACKNOWLEDGMENT}

Experimental diets were kindly provided by Mr. Toru Okada and Aska Parmaceutical Co. Ltd. (Tokyo, Japan). 


\section{REFERENCES}

Bendich A. 1989. Carotenoids and the immune response. Journal of Nutrition 119, 112-115.

Bolin AP, Rita C, Macedo RC, Marin DP, Barros MP, Otton R. 2010. Astaxanthin prevents in vitro auto-oxidative injury in human lymphocytes. Cell Biology and Toxicology 26, 457-467.

Campoio TR, Oliveira FA, Otton R. 2011. Oxidative stress in human lymphocytes treated with fatty acid mixture: Role of carotenoid astaxanthin. Toxicology in Vitro 25, 1448-1456.

Chew BP, Park JS. 2004. Carotenoid action on the immune response. Journal of Nutrition 134, 257S-261S.

Ertesvåg A, Naderi S, Blomhoff HK. 2009. Regulation of B cell proliferation and differentiation by retinoic acid. Seminars in Immunology 21, 36-41.

Fagarasan S, Honjo T. 2003. Intestinal IgA synthesis: regulation of front-line body defences. Nature Immunology 3, 63-72.

Garcia AL, Rühl R, Herz U, Koebnick C, Schweigert FJ, Worm M. 2003. Retinoid- and carotenoid-enriched diets influence the ontogenesis of the immune system in mice. Immunology 110, 180-187.

Goto S, Kogure K, Abe K, Kimata Y, Kitahama K, Yamashita E, Terada H. 2001. Efficient radical trapping at the surface and inside the phospholipid membrane is responsible for highly potent antiperoxidative activity of the carotenoid astaxanthin. Biochimica et Biophysica Acta 1512, 251-258.

Harris NL, Spoerri I, Schopfer JF, Nembrini C, Merky P, Massacand J, Urban JF Jr, Lamarre A, Burki K, Odermatt B, Zinkernagel RM, Macpherson AJ. 2006. Mechanisms of neonatal mucosal antibody protection. Journal of Immunology 177, 6256-6262. 
1 Kume S, Toharmat T. 2001. Effect of colostral $\beta$-carotene and vitamin A on vitamin and health status of newborn calves. Livestock Production Science 68, 61-65.

Mora JR, Iwata M, Eksteen B, Song S, Junt T, Senman B, Otipoby KL, Yokota A, Takeuchi H, Ricciardi-Castagnoli P, Rajewsky K, Adams DH, von Andrian UH. 2006. Generation of gut-homing IgA-secreting B cells by intestinal dendritic cells. Science 314, 1157-1160.

Mora JR, von Andrian UH. 2009. Role of retinoic acid in the imprinting of gut-homing IgA-secreting cells. Seminars in Immunology 21, 28-35.

Morteau O, Gerard C, Lu B, Ghiran S, Rits M, Fujiwara Y, Law Y, Distelhorst EM, Nielsen EM, Hill ED, Kwan R, Lazarus NH, Butcher EC, Wilson E. 2008. An indispensable role for the chemokine receptor CCR10 in IgA antibody-secreting cell accumulation. Journal of Immunoogyl 181, 6309-6315.

Nakamura Y, Nosaka S, Suzuku M, Nagafuchi S, Takahashi T, Yajima T, Takenochi-Ohkubo N. 2004. Dietary fructooligosaccharides up-regulate immunoglobulin A response and polymeric immunoglobulin receptor expression in intestines of infant mice. Clinical and Experimental Immunology 137, 52-58.

Namekawa T, Ikeda S, Sugimoto M, Kume S. 2010. Effects of astaxanthin-containing oil on development and stress-related gene expression of bovine embryos exposed to heat stress. Reproduction in Domestic Animals 45, e387-e391.

Nishida K, Sugimoto M, Ikeda S, Kume S. 2013. Effects of supplemental $\beta$-carotene on mucosal IgA induction in jejunum and ileum of mice after weaning. British Journal of Nutrition doi:10.1017/S0007114513002195.

Nishiyama Y, Sugimoto M, Ikeda S, Kume S. 2011a. Supplemental $\beta$-carotene increases IgA-secreting cells in mammary gland and IgA transfer from milk to neonatal mice. British Journal of Nutrition 105, 24-30. 
1 Nishiyama Y, Yasumatsuya K, Kasai K, Sakase M, Nishino O, Akaike M, Nagase T, Sugimoto M, Ikeda S, Kume S. 2011b. Effects of supplemental $\beta$-carotene with whey on IgA transfer from maternal milk and mucosal IgA induction in neonatal mice and calves. Livestock Science 137, 95-100.

Rühl R. 2007. Effects of dietary retinoids and carotenoids on immune development. Proceedings of the Nutrition Society 66, 458-469.

Statistical Analysis Systems (SAS). 1997. SAS/STAT software: Changes and Enhancement Through Release 6.12 SAS Institute, Cary, NC.

Van del Heijden PJ, Bianchi ATJ., Stok W, Bokhout BA. 1988. Background (spontaneous) immunoglobulin production in the murine small intestine as a function of age. Immunology 65, 243-248.

Wang M, Sugimoto M, Ikeda S, Kume S. 2013. Effects of coumestrol administration to maternal mice during pregnancy and lactation on IgA-secreting cells in mammary gland. Animal Science Journal 84, 322-327.

Zanello G, Meurens F, Serreau D, Chevaleyre C, Melo S, Berri M, D’Inca R, Auclair E, Salmon H. 2013. Effects of dietary yeast strains on immunoglobulin in colostrum and milk of sows. Veterinary Immunology and Immunopathology 152, 20-27. 
1

Table 1 IgA concentrations $(\mu \mathrm{g} / \mathrm{g})$ in serum, feces, jejunum and ileum of the control group after $7(n=8), 14(n=8)$ and $21(n=8)$ days of treatment and the astaxanthin group after $7(n=8), 14(n=9)$ and $21(n=8)$ days of treatment (Mean \pm SE)

\begin{tabular}{lrccc}
\hline & Days & Control & Astaxanthin & $P$ \\
\hline Serum & 7 & $156 \pm 26$ & $123 \pm 17$ & NS \\
& 14 & $163 \pm 12$ & $164 \pm 11$ & NS \\
Feces & 21 & $331 \pm 40$ & $362 \pm 40$ & NS \\
& 7 & $233 \pm 53$ & $235 \pm 49$ & NS \\
Jejunum & 14 & $391 \pm 60$ & $314 \pm 53$ & NS \\
& 21 & $546 \pm 102$ & $508 \pm 77$ & NS \\
& 7 & $751 \pm 83$ & $736 \pm 74$ & NS \\
Ileum & 14 & $880 \pm 92$ & $951 \pm 33$ & NS \\
& 21 & $1049 \pm 91$ & $1487 \pm 99$ & $* *$ \\
& 7 & $628 \pm 75$ & $600 \pm 58$ & NS \\
& 14 & $662 \pm 53$ & $938 \pm 128$ & NS \\
& 21 & $958 \pm 70$ & $1005 \pm 90$ & NS \\
\hline
\end{tabular}

${ }^{* *} P<0.01$, NS, not significant. 
Table 2 The ratios of IgA C-region mRNA to GAPDH mRNA in the jejunum and ileum of the control group after $7(n=8), 14(n=8)$ and $21(n=8)$ days of treatment and the astaxanthin group after $7(n=8), 14(n=9)$ and $21(n=8)$ days of treatment (Mean \pm SE)

\begin{tabular}{lrccc}
\hline & Days & Control & Astaxanthin & $P$ \\
\hline Jejunum & 7 & $0.66 \pm 0.11$ & $0.84 \pm 0.07$ & NS \\
& 14 & $0.85 \pm 0.12$ & $1.27 \pm 0.09$ & $*$ \\
Ileum & 21 & $0.78 \pm 0.07$ & $1.10 \pm 0.08$ & $*$ \\
& 7 & $0.88 \pm 0.16$ & $0.99 \pm 0.11$ & NS \\
& 14 & $1.27 \pm 0.17$ & $1.72 \pm 0.10$ & $*$ \\
& 21 & $0.77 \pm 0.08$ & $0.89 \pm 0.10$ & NS \\
\hline
\end{tabular}

$* P<0.05$, NS, not significant.

GAPDH, glyceraldehyde-3-phosphate dehydrogenase 
1
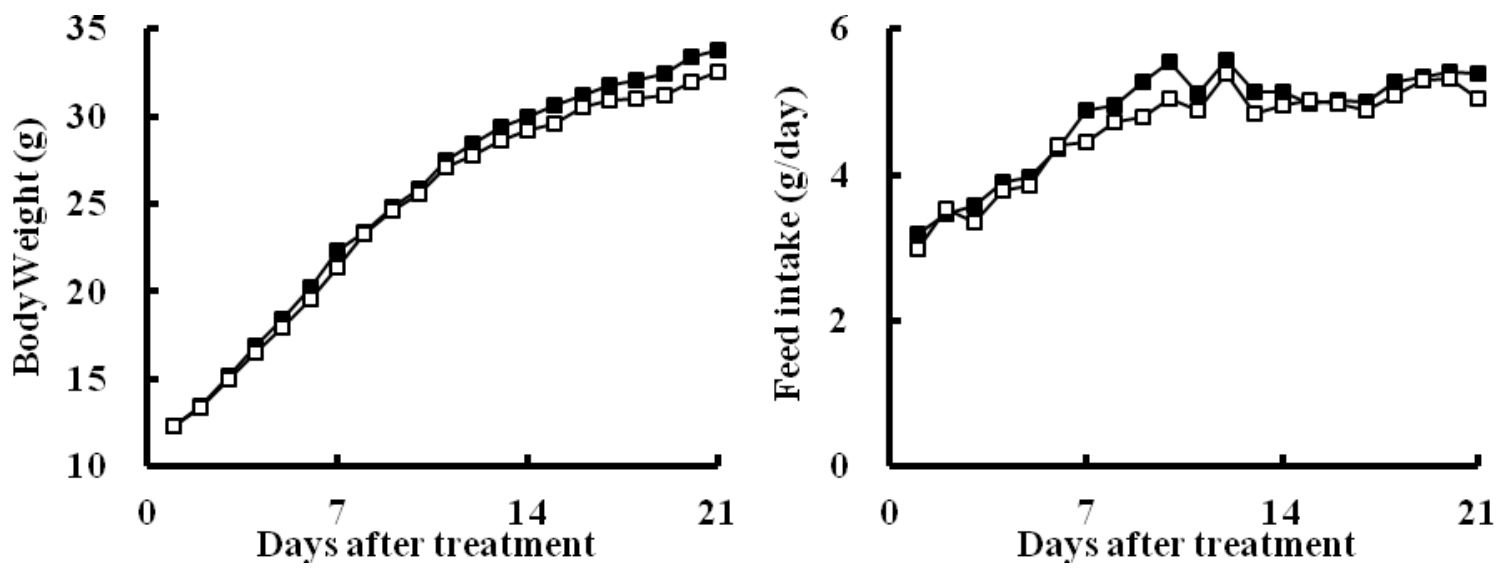

3 Figure 1 Body weights and feed intake of the control $(\mathbf{m} ; n=8)$ and $\beta$-carotene $(\square ; n=8)$

4 groups during 21days of treatment.

5 
1

2

a) Jejunum

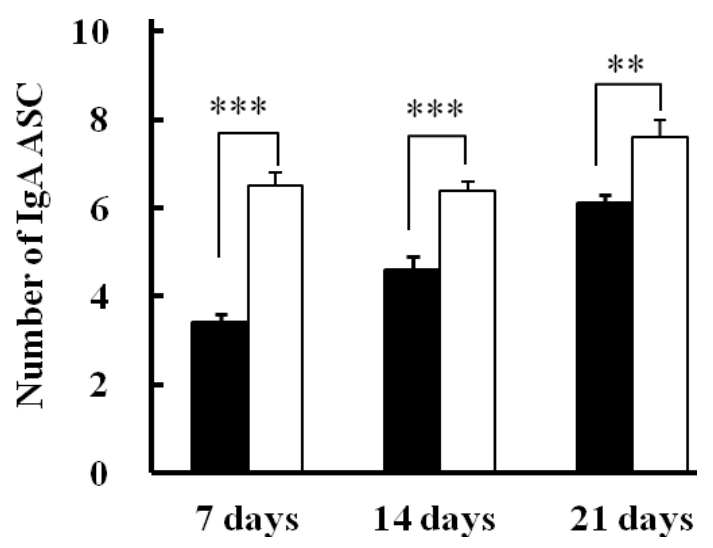

b) Ileum

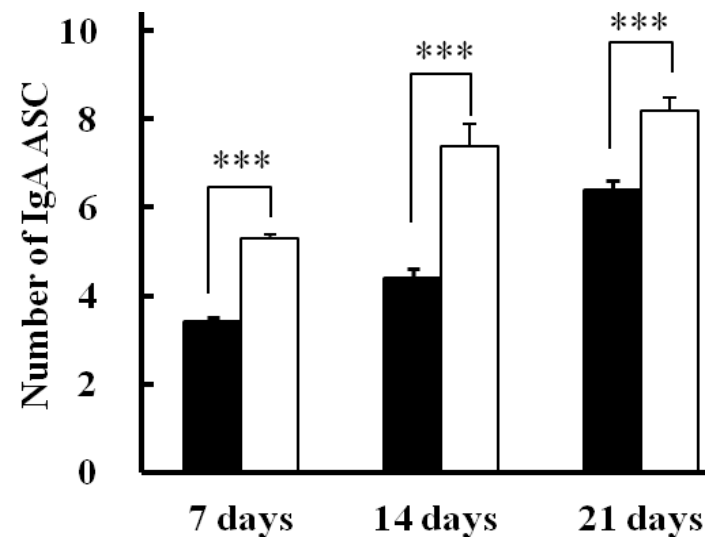

4 Figure 2 Numbers of IgA antibody-secreting cells (ASC) in the jejunum and ileum of the control group ( $\mathbf{a})$ after $7(n=8), 14(n=8)$ and $21(n=8)$ days of treatment and the astaxanthin group ( $\square$ ) after $7(\mathrm{n}=8), 14(\mathrm{n}=9)$ and $21(\mathrm{n}=8)$ days of treatment (Mean \pm SE). The numbers

7 of IgA ASC in the jejunum and ileum were counted in the lamina propria of villi in eight randomized

$8 \quad$ villi from each mouse.

9

${ }^{* * *} P<0.001,{ }^{* *} P<0.01$. 